\title{
Expression of nodule-specific genes in alfalfa root nodules blocked at an early stage of development
}

\author{
Rebecca Dickstein, ${ }^{1}$ Ton Bisseling, ${ }^{2}$ Vernon N. Reinhold, ${ }^{3}$ and Frederick M. Ausubel ${ }^{1}$ \\ ${ }^{1}$ Department of Genetics, Harvard Medical School and Department of Molecular Biology, Massachusetts General Hospital, \\ Boston, Massachusetts 02114 USA; $^{2}$ Department of Molecular Biology, Agricultural University, 6703 BC Wageningen, The \\ Netherlands; ${ }^{3}$ Department of Nutrition, Harvard School of Public Health, Boston, Massachusetts 02115 USA
}

To help dissect the molecular basis of the Rhizobium-legume symbiosis, we used in vitro translation and Northern blot analysis of nodule RNA to examine alfalfa-specific genes (nodulins) expressed in two types of developmentally defective root nodules elicited by $R$ hizobium meliloti. Fix ${ }^{-}$nodules were elicited by $R$. meliloti nif mutants; these nodules were invaded by rhizobia and contained differentiated bacteroids. 'Empty' nodules were elicited by $R$. meliloti exo and $n d v$ mutants and by Agrobacterium tumefaciens strains carrying the $R$. meliloti nod genes; these nodules contained a nodule meristem but lacked infection threads, intracellular bacteria, and bacteroids. Fix ${ }^{-}$nodules contained a spectrum of nodulins similar to wild-type nodules. In contrast, only two nodulins, Nms-30 and a nodulin homologous to ENOD2 of soybean, were detected in empty nodules. Although $R$. meliloti ndv and exo mutants elicited nodules with the same defective phenotype, $n d v$ and exo mutants (except for exoC mutants) had distinct biochemical phenotypes. $R$. meliloti $n d v A$ and $n d v B$ mutants were deficient in cyclic glucan production but not the acidic exopolysaccharide; the converse was true for exoA, exoB, and exoF mutants. exoC mutants were defective in both exopolysaccharide and cyclic glucan biosynthesis. Our results support the model that the $R$. meliloti nod genes produce a signal that results in nodule meristem induction. Both the exopolysaccharide and cyclic glucan, however, appear to act at the next step in the developmental process and are involved in the production of a signal (or structure) that allows infection thread formation and invasion of the nodule.

[Key Words: Nodulins; symbiosis; nitrogen fixation; exopolysaccharides; cyclic glucan; developmental mutants]

Received November 30, 1987; revised version accepted April 12, 1988.

Rhizobia are able to fix nitrogen in symbiotic cooperation with legumes. Nitrogen fixation takes place in nodules, highly specialized organs that develop specifically for the purpose of nitrogen fixation. Both rhizobial and plant mutants that affect nodule development at specific stages have been isolated, indicating that plant and bacterial differentiation is coordinated by the passage of signal molecules from one symbiotic partner to the other. The molecular basis of the intracellular communication is still largely unknown (for general reviews, see Verma and Long 1983; Halverson and Stacy 1986).

Recently, it has been shown that plant flavones act as species-specific signal molecules early in the differentiation process by activating the expression of Rhizobium nod genes (Peters et al. 1986; Redmond et al. 1986). Although its composition is unknown, genetic studies suggest that a subsequent signal is generated by the Rhizobium nod genes, which results in nodule meristem induction (see below). Nod genes are defined phenotypically as symbiotic genes that are required for the elicitation of nodules. All Rhizobium species studied to date have two categories of nod genes. Common nod genes, as the name implies, are found in all Rhizobium species and have been both functionally and structurally conserved in evolution (Kondorosi and Kondorosi 1986). Host-specific nodulation genes, however, may be species specific and appear to be involved in mediating host-specific interactions.

The primary evidence that the nod-gene product|s) signal the plant host to initiate nodule development is the observation that Agrobacterium tumefaciens strains can be engineered to elicit organized root nodules by transfer of a recombinant plasmid carrying the Rhizobium meliloti common (nodABCD) and host-specific (nodEFGH) nod genes (Hirsch et al. 1984; Truchet et al. 1985). However, these $A$. tumefaciens-elicited nodules display what has come to be called an 'empty' nodule phenotype; they lack infection threads, intracellular bacteroids, and peribacteroid membranes (Hirsch et al. 1984; Truchet et al. 1985). These results suggested that in addition to the nod genes, $R$. meliloti symbiotic genes are required for infection thread formation and bacteroid development.

One predicted feature of $R$. meliloti symbiotic genes that act in the developmental process at the stage following the action of the nod genes is that $R$. meliloti 
strains carrying mutations in such genes should elicit empty nodules. $R$. meliloti mutants defective in either the biosynthesis of the acidic exopolysaccharide lexo mutants) or mutants defective in the biosynthesis of an extracellular cyclic glucan (ndv 'nodule development' mutants) elicit empty nodules (Finan et al. 1985; Dylan et al. 1986). Because the ultrastructural features of nodules elicited by exo and $n d v$ mutants are similar to $A$. tumefaciens-elicited nodules, it appears likely that the exo and $n d v$ genes act at the stage in nodule development directly following the stage at which the nod genes act.

The empty nodule phenotype is not a consequence of the failure of the $R$. meliloti endosymbiont to fix nitrogen. Defective nodules are also elicited by $R$. meliloti nif and fix mutants; these Fix ${ }^{-}$nodules, however, contain infection threads, intracellular bacteroids, and peribacteroid membranes. In addition, $\mathrm{Fix}^{-}$nodules contain all of the plant-synthesized, nodule-specific proteins and RNAs for which antibody and cDNA probes are available, whereas empty nodules elicited by $R$. meliloti exo mutants synthesize only a subset of nodule-specific proteins (Lang-Unnasch et al. 1985; Dunn et al. 1988).

In this study, we sought to determine whether empty nodules elicited by $R$. meliloti exo and $n d v$ mutants or by $A$. tumefaciens carrying the $R$. meliloti nod genes share biochemical, as well as ultrastructural, features. If this were the case, it would provide support for the developmental model that the exo-and ndv-gene products act at a stage in the symbiosis directly following the action of the nod-gene products. Specifically, we analyzed RNA isolated from a variety of empty nodules for the presence of nodule-specific mRNAs. We find that all empty nodules express a common and very limited number of nodulin genes, whereas nodules that are invaded and contain differentiated bacteroids express the same spectrum of nodulins as wild-type nodules. In addition, we show that $R$. meliloti ndv mutants are deficient in cyclic glucan production but produce the acidic exopolysaccharide and that the converse is true for several exo mutants, except exoC, which is deficient in both the cyclic glucan and exopolysaccharide.

\section{Results \\ Structure of mutant nodules}

The morphological phenotypes of nodules elicited by $R$. meliloti nifH, exo, and ndv mutants and by $A$. tumefaciens strains containing $R$. meliloti nod genes have been described previously (Hirsch et al. 1983, 1984; Leigh et al. 1985; Truchet et al. 1985; Dylan et al. 1986). To confirm that the mutant nodules used for the biochemical experiments described in this paper displayed the ultrastructural phenotypes described previously, we used phase contrast microscopy to examine $1-\mu \mathrm{m}$ sections of nodules elicited on alfalfa (variety Iroquois) by $R$. meliloti strains $\mathrm{Rm} 1021$ (wild-type), $\operatorname{Rm} 7023$ (exoA), RmndvA-LI (ndvA), RmndvB-Ty7 (ndvB), and Rm1492 (nifH) and by $A$. tumefaciens strain 136/pMH36. [The recombinant plasmid pMH36 carries the $R$. meliloti $\operatorname{nod} A B C, \operatorname{nodD}, \operatorname{nod} H$, and nodEFG genes; it consists of a $29.1-\mathrm{kb}$ insert from the $R$. meliloti $\mathrm{pSym}$ plasmid in the cosmid cloning vector pLAFR1 (Friedman et al. 1982).]

In confirmation of previously published results cited above, we observed that the empty nodules elicited by $R$. meliloti exo and $n d v$ mutants and by $A$. tumefaciens 136/pMH36 were ultrastructurally indistinguishable (data not shown). On the other hand, we did observe that $R$. meliloti exo and $n d v$ mutants elicited numerous very small nodules that resembled beads on a string, whereas the $A$. tumefaciens strains elicited fewer and larger nodules, whose time of appearance was delayed relative to nodules elicited by exo or $n d v$ mutants. Nodules elicited by the $R$. meliloti nifH mutant strain Rm1492 were very similar ultrastructurally to wild-type nodules; this is also in accordance with results reported previously (Hirsch et al. 1983).

\section{In vitro translation of $m R N A$ from empty nodules}

We extracted RNA from alfalfa nodules elicited by wildtype $R$. meliloti, by various $R$. meliloti mutants, and by $A$. tumefaciens strains containing the $R$. meliloti nod genes. The RNA was analyzed for expression of nodulespecific alfalfa genes by in vitro translation in a rabbit reticulocyte system followed by two-dimensional gel electrophoretic analysis (Fig. 1). Figure 1, panels A and B, compares the in vitro translation products of RNA isolated from wild-type alfalfa nodules and from uninoculated alfalfa roots. Similar results have already been reported by Dunn et al. (1988) but are reproduced here for ease of comparison with the results obtained from translating RNA from empty nodules. About 20 nodule-specific translation spots were detected in nodules that were not present in the two-dimensional gels of in vitro translations of root tissue RNAs. Longer exposures of the autoradiographs of these gels gave the same results.

In marked contrast to the results obtained with RNA isolated from wild-type nodules, when the in vitro translation products of RNA isolated from empty nodules were analyzed, only one of the nodule-specific translation products, $30 \mathrm{kD}$ in size (now called Nms-30 for nodulin, Medicago sativa, $30 \mathrm{kD}$ / was detected. (Occasionally, we also detected a minor translation product that was also $\sim 30 \mathrm{kD}$ but was slightly more basic than the major $30 \mathrm{kD}$ translation spot.) We observed the same pattern of in vitro translation spots with RNAs isolated from nodules elicited by several different exopolysaccharide (exo) mutants [Rm7023 (exoA), Rm7094 (exoB), $\operatorname{Rm} 7020$ (exoC), $R m 7055$ (exoF)], by $n d v$ mutants (RmndvB-TY7, RmndvB-TY9, and RmndvA-LI), and by three different $A$. tumefaciens strains carrying $R$. meliloti nod genes (136/pMH36, 348/pMH36, and 1038/ pMH36). Representative results are shown in Figure 1, panels D-F.

In the case of RNA isolated from empty nodules elicited by A. tumefaciens strains 136/pMH36 and 348/ pMH36, the same translation products were obtained, regardless of whether the $A$. tumefaciens strain contained the Ti plasmid. A. tumefaciens strain 348 is a 
wild-type strain and strain 136 is a derivative of 348 that has been cured of its Ti plasmid. This result indicated that $\mathrm{Nms}-30$ is not produced as part of a general re- sponse to pathogenic bacteria. In support of this interpretation, no nodule-specific translation products were detected with RNA isolated from alfalfa roots that had

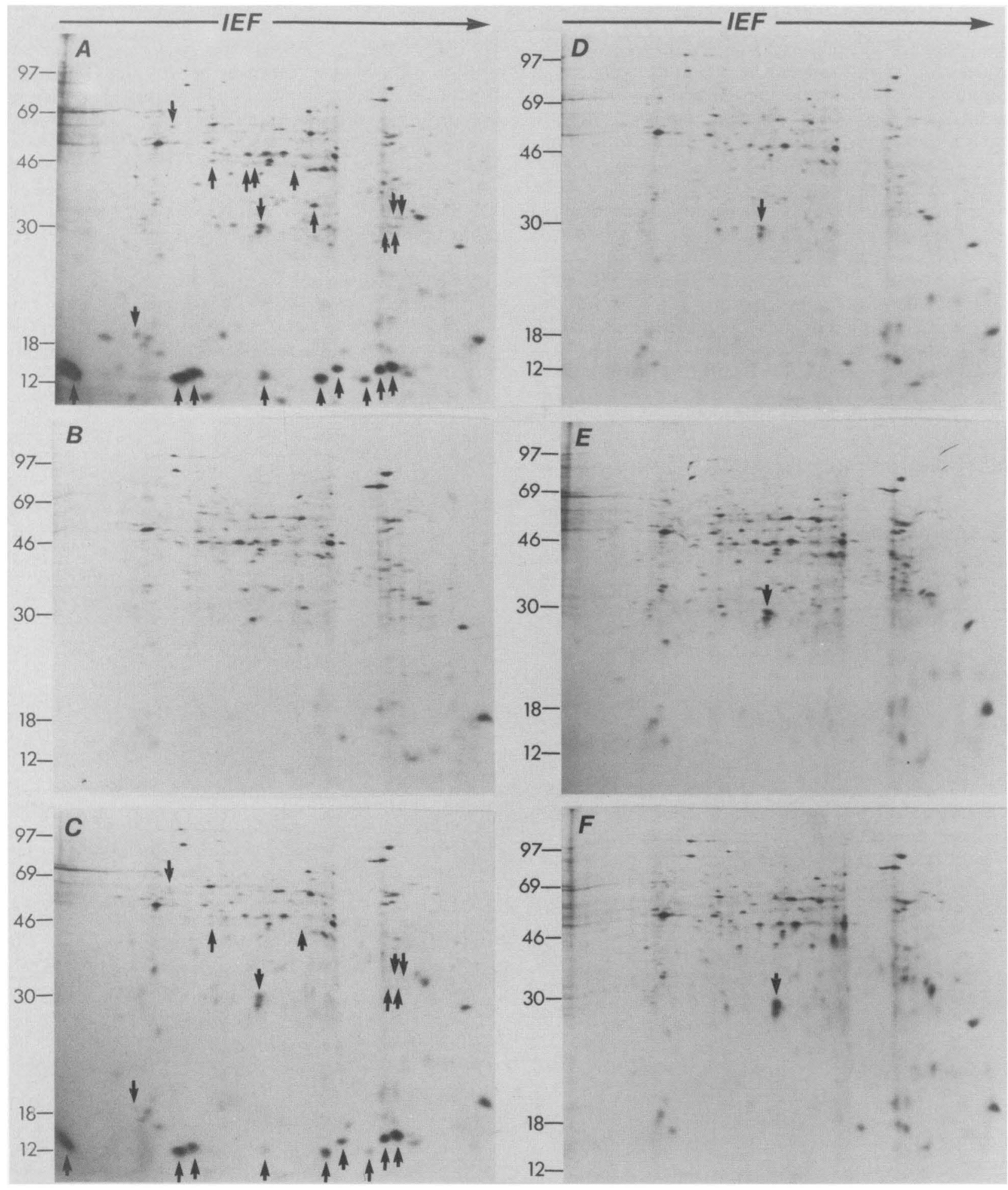

Figure 1. Nodule-specific gene expression. In vitro translation and two-dimensional gel analysis of total RNA extracted from alfalfa. Isoelectric focusing was from right to left, as indicated, resulting in a pH gradient of 6.9 (left) to 3.9 (right). (A) Fix ${ }^{+}$nodules elicited by $R$. meliloti $1021 ;(B)$ uninoculated roots; $(C)$ Fix nodules elicited by $R$. meliloti $1492(\text { nifH })_{i}(D)$ empty nodules elicited by $R$. meliloti $7094(e x O B)_{;}(E)$ empty nodules elicited by $R$. meliloti ndvB-TY7; $(F)$ empty nodules elicited by $A$. tumefaciens $1038 / \mathrm{pMH} 36$. Arrows point to nodule-specific translation spots. 
been grown in the presence of either $A$. tumefaciens strain 136 or 348 (i.e., not carrying pMH36) (data not shown).

The $R$. meliloti $n d v A$ and $n d v B$ genes were isolated on the basis of their homology to the $A$. tumefaciens $\operatorname{chv} A$ and $\operatorname{chv} B$ genes, respectively (Dylan et al. 1986). The $A$. tumefaciens $\operatorname{chv} A$ and $\operatorname{chv} B$ genes are involved in the synthesis of a cyclic $\beta(1 \rightarrow 2)$ glucan (Puvanesarajah et al. 1985), are located on the chromosome (not on the $\mathrm{Ti}$ plasmid), and are required for attachment of $A$. tumefaciens to wounded plant tissue (Douglas et al. 1982, 1985). Because the R. meliloti $n d v A$ and $n d v B$ genes are not required to elicit a nodule structure, we reasoned that the $A$. tumefaciens $c h v$ genes would not be required to elicit a nodule in $A$. tumefaciens strains carrying the $R$. meliloti nod genes. To test this hypothesis, pMH36 (carrying the $R$. meliloti nod genes) was conjugated into A. tumefaciens 1038 (chvB). A. tumefaciens 1038/ pMH36 elicited alfalfa nodules morphologically similar to wild-type $A$. tumefaciens strains carrying pMH36, and RNA isolated from these nodules yielded the same translation products found in other empty nodules (Fig. 1 , panel F). The $R$. meliloti ndv mutants used in the experiments shown in Figure 1 were constructed in a different genetic background of $R$. meliloti than the exo strains and the other $R$. meliloti strains used in this study (Rm102F34 instead of Rml021). Therefore, as a control, we examined the translation pattern of RNA isolated from nodules elicited by wild-type Rm102F34nal ${ }^{R}$ and found it to be identical to the Rm1021 nodule RNA translation pattern (data not shown).

We also analyzed RNA extracted from nodules elicited by a $R$. meliloti nifH mutant. nifH codes for one of three polypeptide subunits of nitrogenase, the nitrogen-fixing enzyme. Nodules elicited by nif $H$ mutants are obviously defective in nitrogen fixation, but ultrastructural studies have shown that they are fully invaded, containing infection threads, bacteroids, and peribacteroid membranes (Hirsch et al. 1983). Moreover, these $\mathrm{Fix}^{-}$nodules have been shown to synthesize a variety of nodulins, including leghemoglobin, as determined by immunological (Lang-Unnasch and Ausubel 1985) and Northern blot analyses (Dunn et al. 1988). Figure 1, panel C, shows that translation of RNA isolated from the $\mathrm{Fix}^{-}$nodules elicited by Rm1492 (nifH) yields most (but not all) of the nodulin spots that are present in wild-type nitrogenfixing nodules. This result showed that the presence of a single nodule-specific translation product (i.e., $\mathrm{Nms}-30$ ) in our translation assay is a specific feature of empty nodules, rather than a general feature of all defective Fix $^{-}$nodules.

\section{Northern blot analysis of RNA from empty nodules}

To obtain additional evidence that empty nodules elicited by different $R$. meliloti mutants and by $A$. tumefaciens strains carrying pMH36 synthesize the same limited set of nodule-specific mRNAs, we sought to identify additional nodulins in empty nodules other than
Nms-30. Because empty nodules appear to be blocked at an early stage of nodule development (i.e., prior to the formation of infection threads), we reasoned that nodulins expressed in empty nodules might be those nodulins that are normally expressed early in the nodulation process. Nms-30 was found to be structurally related to one of the earliest detectable pea nodulins, $\mathrm{N}-40$ ' (Govers et al. 1985); antibodies to $\mathrm{N}-40^{\prime}$ precipitate Nms-30 (T. Bisseling, unpubl.). In the case of pea, at least two other nodulins have been detected whose appearance precedes that of the bulk of nodulins, including leghemoglobin (Govers et al. 1985, 1986). One of these is homologous to the soybean N-75 gene, also called ENOD2. A cDNA corresponding to soybean N-75 has been cloned and sequenced (Franssen et al. 1987). The translated amino acid sequence is $45 \%$ proline and is characterized by 30 repeating heptapeptide units.

To determine whether alfalfa synthesizes a nodulin homologous to soybean N-75, a degenerate oligonucleotide probe was synthesized that codes for the repeat heptapeptide sequence (see Materials and methods). This probe was used to identify homologous sequences in an alfalfa nodule cDNA library constructed in $\lambda$ gt 11 ; hybridizing clones were found at a frequency of $\sim 1$ in $10^{4}$. One cDNA clone was subcloned into the plasmid Bluescribe and called pBl-A2ENOD2. DNA sequence analysis of A2ENOD2 showed that this cDNA is $81 \%$ homologous to soybean N-75 at the DNA level and $70 \%$ at the translated amino acid level (see Materials and methods and Fig. 2). As described in Materials and methods, a 0.4-kb cDNA, pBl-17, coding for leghemoglobin, was also isolated from the $\lambda$ gt1l library, subcloned, and used as a control in the following experiments.

Total RNA from wild-type nodules, from nodules elicited by $R$. meliloti mutants, and from nodules elicited by A. tumefaciens strains carrying pMH36 was run on agarose gels containing formaldehyde, blotted to GeneScreen, and hybridized with the A2ENOD2 and leghemoglobin cDNA probes. RNA that hybridized to A2ENOD2 was detected in all nodule tissues examined (Fig. 3, panel A, lanes 1-12), but was not expressed in nonnodule tissues, such as etiolated seedling, root, or leaf (lanes 13-16). In contrast, RNA that hybridized to the leghemoglobin cDNA probe was only detected in wild-type nodules and $\mathrm{Fix}^{-}$nodules elicited by the $R$. meliloti nifH mutant (Fig. 3, panel B). As a control, the blot was stripped and rehybridized to an alfalfa ribosomal cDNA clone, $\mathrm{pB1}-18 \mathrm{r}$, to demonstrate the presence of RNA in each lane (Fig. 3, panel C). Both A2ENOD2 and leghemoglobin RNAs were found in the polyadenylated RNA fraction (Fig. 3, lane 1).

\section{Cyclic $\beta(1 \rightarrow 2)$ glucan synthesis by R. meliloti exo mutants}

One possible explanation for the fact that both $R$. meliloti exo and $n d v$ mutants elicit empty nodules with the same phenotypic features is that both types of mutants 
A

\section{1}

41

cgaccacatgitgcatccaccgccagagcatcaAccaccti

81

TTGAACATCCACCGCCAGA

121

ACCGCCACAT̈GTGCATCCACCACCTGAGTACCAACCTCCT

161

201

241

281
B

2 PHVHPPPEHQPPLEHPPPEYQPPHEKPPHVHPPPEYQPPY

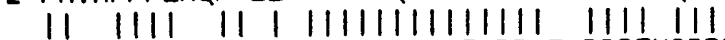
13 PHEKPPPEYLPPHEKPPPEYQPPHEKPPHENPPPEHQPPH 42 QKPPHEKSPYEPPPQEYQPP HEK.PPQVKPPSEYQPPHEK

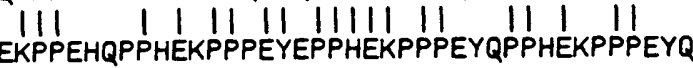

82 PPHEHPPPEYQQPPHEKP 97

||I| ||||||||||||

93 PPHEKPPPEYQPPHEKP 109

Figure 2. (A) Nucleotide sequence of A2ENOD2. $(B)$ Translated peptide sequence of A2ENOD2 (top) compared with translated peptide sequence of soybean N-75 (bottom). Vertical bars indicate an exact match.

are defective in either or both exopolysaccharide and cyclic $\beta(1 \rightarrow 2)$ glucan synthesis. To investigate this possibility, we analyzed $R$. meliloti exo and $n d v$ mutants for the production of exopolysaccharide and cyclic $\beta(1 \rightarrow 2)$ glucan. As described above, $R$. meliloti exo genes are required for the biosynthesis of an exported acidic exopolysaccharide that binds the fluorescent dye Calcofluor (Leigh et al. 1985), and the R. meliloti ndvB gene is homologous to and functionally interchangeable with the A. tumefaciens $c h v B$ gene. A. tumefaciens $c h v$ and $R$. meliloti $n d v$ mutants are defective in the synthesis of a periplasmically located cyclic $\beta(1 \rightarrow 2)$ glucan (Douglas et al. 1985; Dylan et al. 1986; Geremia et al. 1987; T. Dylan, L. Ielpi, and G. Ditta, pers. comm.).

We confirmed that $R$. meliloti ndv mutants are not deficient in the synthesis of the Calcofluor-binding exopolysaccharide (Dylan et al. 1986; Geremia et al. 1987) by observing fluorescent colonies on Calcofluor plates (Table 1). To rule out the possibility that $R$. meliloti exo mutants are deficient for both exopolysaccharide and cyclic $\beta(1 \rightarrow 2)$ glucan production, we analyzed $R$. meliloti exo mutants for the production of cyclic $\beta(1 \rightarrow 2)$ glucan. $R$. meliloti strains (and $A$. tumefaciens strains as controls| were grown under low osmotic conditions to maximize cyclic $\beta(1 \rightarrow 2)$ glucan production (Miller et al. 1986). Cell-associated trichloroacetic acid (TCA)-extractable oligo- and polysaccharides were prepared and separated by size on a Sephadex G-50 column according to the method of Miller et al. (1986) (for details; see Materials and methods). Four criteria were used to identify and characterize the cyclic $\beta(1 \rightarrow 2)$ glucan product: $(1)$ comparison of column elution time to that previously reported (Miller et al. 1986), (2) comparison of wild-type extracts to extracts from bacteria known to be cyclic glucan deficient, (3) linkage and glycan composition data obtained by gas-liquid chromatography-mass spectroscopy (GLC-MS), and (4) molecular-weight analysis by direct chemical ionization-mass spectroscopy (DCI-MS).

The Sephadex elution profiles obtained from extracts of wild-type $A$. tumefaciens (Fig. 4A) were comparable to earlier published work (Miller et al. 1986), tentatively identifying the intermediate eluting carbohydrate as cyclic glucan (large arrow). This component was absent in extracts prepared from $A$. tumefaciens strain 1038, a $c h v B$ mutant defective in cyclic glucan production (Fig. 4B). The expected cyclic glucan fractions were pooled

\section{$\begin{array}{lllllllllllllllll}1 & 2 & 3 & 4 & 5 & 6 & 7 & 8 & 9 & 10 & 11 & 12 & 13 & 14 & 15 & 16\end{array}$}

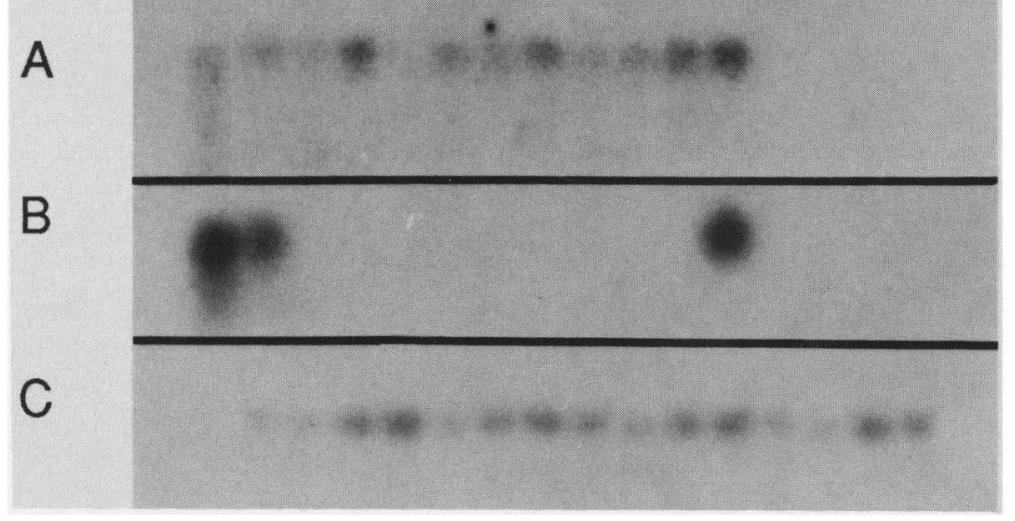

Figure 3. Northern blot analysis of total alfalfa RNA. (Lane 1) poly(A) ${ }^{+}$RNA from $\mathrm{Fix}^{+}$nodules elicited by Rm1021. Total RNA from nodules elicited by Rm1021 (wild type) (lane 2); Rm7023 (exoA) (lane 3); Rm7094 (exoB) (lane 4); Rm7055 (exoF) (lane 5); $\operatorname{Rm} 7020$ (exoC) (lane 6); Rm ndvA-LI (lane 7); Rm ndvB-Ty7 (lane 8); At136/pMH36 (lane 9); At348/pMH36 (lane 10); At1038/pMH36 (lane 11); Rm1492 (nifH) (lane 12). Total RNA from uninoculated seedling (lane 13); roots grown in the presence of At136 (lane 14); roots grown in the presence of At348 (lane 15); leaves (lane 16). The blots were probed with pA2ENOD2 $(A)$; leghemoglobin cDNA $(\mathrm{pBl}-17)(B) ;$ and ribosomal cDNA (pBl-18r) $(C)$. ENOD2 mRNA is $1.3 \mathrm{~kb}$, leghemoglobin mRNA is $0.6 \mathrm{~kb}$; and the rRNA detected is $2.4 \mathrm{~kb}$. 
Table 1. Phenotypic characteristics of R. meliloti mutant strains and A. tumefaciens strains harboring $\mathrm{R}$. meliloti nod genes

\begin{tabular}{|c|c|c|c|c|c|c|}
\hline \multirow[b]{3}{*}{ Strain } & \multicolumn{2}{|c|}{ Carbohydrate } & \multirow{2}{*}{\multicolumn{4}{|c|}{ Plant response }} \\
\hline & \multirow[b]{2}{*}{ exo } & \multirow{2}{*}{$\begin{array}{l}\text { cyclic } \\
\text { glucan }\end{array}$} & & & & \\
\hline & & & nodule & $30 \mathrm{kD}$ & ENOD2 & $\overline{\mathrm{Lb}}$ \\
\hline $\mathrm{Rm} 1021$ & + & + & $\mathrm{Fix}^{+}$ & + & + & + \\
\hline $\operatorname{exo} A$ & - & + & empty & + & + & - \\
\hline$e x o B$ & - & + & empty & + & + & - \\
\hline exoC & - & - & empty & + & + & - \\
\hline exoF & - & + & empty & + & + & - \\
\hline$n d v A$ & + & - & empty & + & + & - \\
\hline$n d v B$ & + & - & empty & + & + & - \\
\hline \multicolumn{7}{|l|}{ At136/ } \\
\hline pMH36 & + & + & empty & + & + & - \\
\hline \multicolumn{7}{|l|}{ At346/ } \\
\hline pMH36 & + & + & empty & + & + & - \\
\hline \multicolumn{7}{|l|}{ Atl038/ } \\
\hline pMH36 & + & - & empty & + & + & - \\
\hline
\end{tabular}

and submitted to linkage and composition analysis using GLC and GLC-MS. These data indicated the presence of only one glucan and linkage type: 2-linked glucose, with a detectable peak corresponding to terminal glucose $(\sim 1: 20)$. Control studies with $\beta$-cyclodextran indicated that detection of terminal glucose residues was not due to a degradation product of permethylation (Dell et al. 1983). Instead, the terminal residue may have arisen from a linear contaminating glucan cochromatographying with the major component or could have been due to glucose leaching from the column packing material.

Extracts from wild-type and mutant $R$. meliloti were subjected to similar analysis. Figure 4, panel C, depicts Sephadex G-50 column fractionation data obtained from wild-type $R$. meliloti strain 102F34nal ${ }^{R}$, the parental strain of the $n d v$ mutants. Wild-type $R$. meliloti strain 1021 extracts gave similar results. The cyclic glucan peaks from Rm102F34nal ${ }^{R}$ and Rm1021 extracts, which eluted at the same position as the cyclic glucan from $A$. tumefaciens (large arrows), were also subjected to linkage and composition analysis and gave identical results to the cyclic glucan from A. tumefaciens. As expected, we could not detect cyclic glucan from the $n d v A$ mutant (Fig. 4, panel D) or the $n d v B$ mutant. However, using comparable analysis, cyclic glucan was found in the exOA (Rm7023) mutant (Fig. 4, panel E, large arrow). Linkage and composition analysis again indicated that this cyclic glucan sample consisted of 2-linked glucose, with terminal glucose present at a ratio of $1: 20$. Convincing proof for a cyclic glycan structure was provided by molecular-weight analysis of the permethylated fractions using DCI-MS (see Materials and methods). These data (not shown) were consistent only with a series of cyclic glycans $(\mathrm{Glc})_{n}$, where $n=20-26$. (A linear glycan is 18 daltons higher in molecular weight than the corresponding cyclic glycan.) Cyclic glucan was also found in the exoB (Rm7094) and exoF (Rm7055) mutants.

The R. meliloti exoC mutant was found to be different from either the other exo mutants or the $n d v$ mutants that we examined: it was defective in both exopolysaccharide and cyclic glucan biosynthesis. The $R$. meliloti exoC mutant was deficient in all TCA-extractable oligoand polysaccharides, including the cyclic $\beta(1 \rightarrow 2)$ glucan (Fig. 4, panel F). However, one complication in the analysis of the $R$. meliloti exoC mutant was that the exoC mutant failed to grow in the low osmotic YM medium that was used to grow the other strains; supplementation with $0.2 \mathrm{M} \mathrm{NaCl}$ was optimal for growth, and and TCA extracts were made from cultures grown in 0.1 M NaCl. Miller et al. (1986) have shown that $A$. tumefaciens regulates cyclic $\beta(1 \rightarrow 2)$ glucan production osmotically, producing the highest amounts of cyclic $\beta(1 \rightarrow 2)$ glucan under conditions of low osmolarity. Indeed, we found that when TCA extracts of Rm1021 grown in YM containing $0.1 \mathrm{M} \mathrm{NaCl}$ were analyzed by Sephadex G-50, the peak corresponding to cyclic glucan was diminished by $\sim 60 \%$ relative to total carbohydrate extracted.

Chromatographic analysis of the carbohydrates from the cyclic glucan-deficient $A$. tumefaciens chv $B$ mutant revealed that it contained an oligosaccharide lopen arrow, Fig. 4B) which eluted close to the cyclic glucan elution position. Linkage analysis indicated that this glycan was composed of 4- or 6-linked hexose units. A similar quantity of this material was found in the $R$. meliloti $n d v B$ mutant TCA extract. None of the other strains examined appeared to contain a significant quantity of this material.

We believe the material that elutes at the excluded volume of the column (labeled $V_{e}$ ) is exopolysaccharide. Its presence or absence correlates with the appearance of fluorescent colonies on Calcofluor plates.

A summary of the results is given in Table 1 .

\section{Discussion}

We have begun to examine the $R$. meliloti-alfalfa symbiotic interaction from the plant's perspective: examining which nodule-specific genes are expressed when wild-type alfalfa interacts with a variety of mutant $R$. meliloti strains. The strategy is to utilize $R$. meliloti symbiotic mutants to help define specific stages in nodule development. We have focused past efforts on nodulins that are synthesized relatively late during nodule development and found that cDNAs representing five such nodulins: leghemoglobin, nodule-specific glutamine synthetase, N-14, N-22, and N-34/35 (Dunn et al. 1988) are all expressed in invaded nodules elicited by wild-type $R$. meliloti or by a $R$. meliloti nifH mutant but were absent from so-called empty nodules elicited by a $R$. meliloti exo mutant. In the present study, we examined the expression of nodulin genes in empty nodules elicited by $R$. meliloti exo and $n d v$ mutant or by $A$. tumefaciens strains carrying the $R$. meliloti nod genes cloned on plasmid pMH36. Among the nodule-specific products that we can detect by in vitro translation of nodule RNA or by hybridization of nodule RNA to cloned nodule-specific cDNAs, only two, nodulins Nms-30 and a mRNA homologous to ENOD2 cDNA from soybean (which codes for nodulin N-75), were de- 

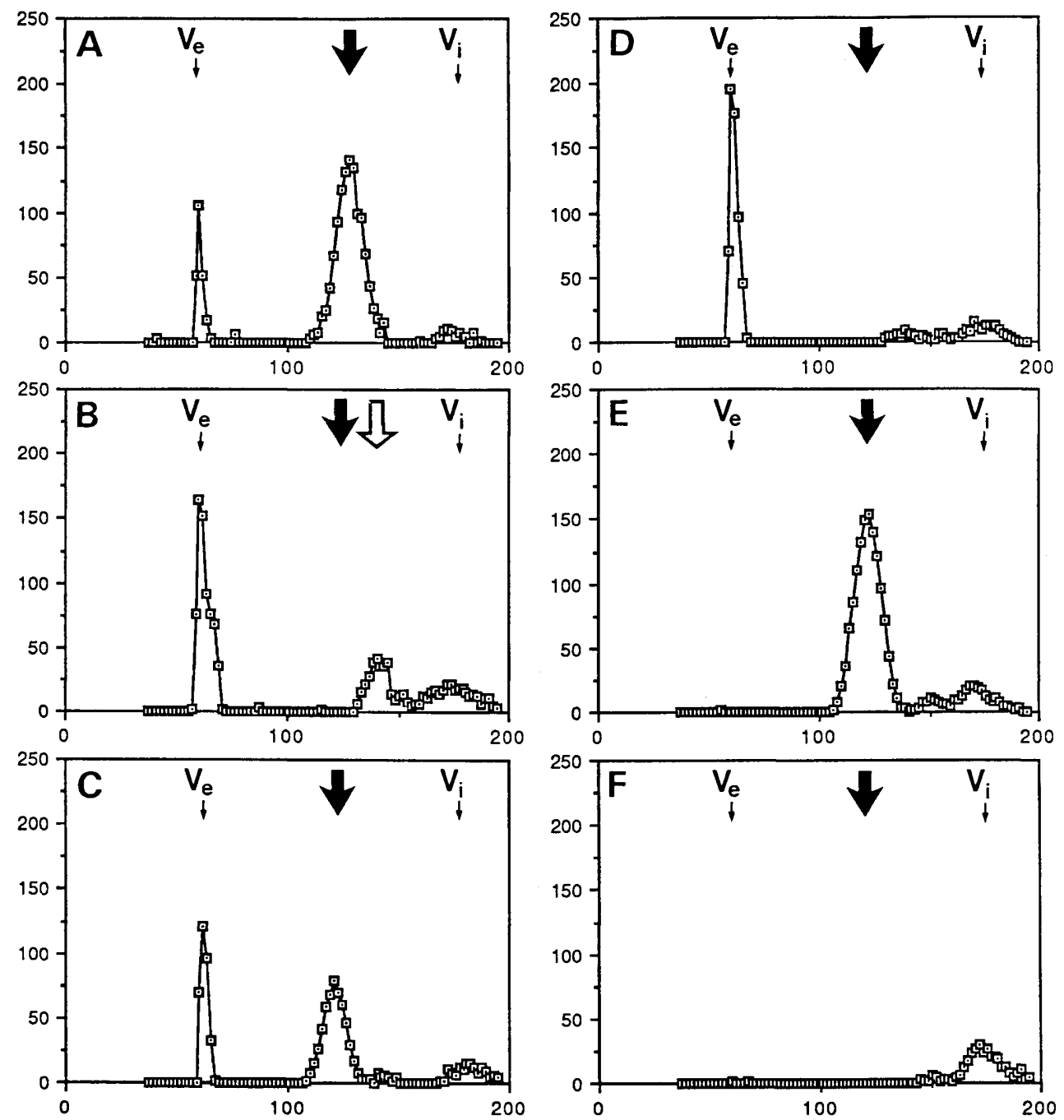

Figure 4. Size fractionation of extracted cellular carbohydrates. Cellular carbohydrates were fractionated on Sephadex G-50, and the total hexose content of the fractions was determined as described in Materials and methods. $(A)$ At348, wild type; $(B)$ At1038 $(c h v B$; cyclic glucan deficient); (C) Rm1021 (wild type); $(D) \mathrm{Rm}$ ndvA-LI (ndvA; cyclic glucan deficient); $(E)$ Rm7023 (exoA; exopolysaccharide deficient); $(F) \mathrm{Rm} 7020$ (exoC; cyclic glucan and exopolysaccharide deficient) grown in $0.1 \mathrm{M} \mathrm{NaCl}$. Small arrows point to the excluded and included volumes; large arrows point to the elution position of cyclic glucan. The open arrow in $B$ points to a carbohydrate that contains either 4- or 6-linked sugars. Values are given as micrograms of hexose per milliliter.

tected in these empty nodules. [An alfalfa cDNA clone (A2ENOD2) homologous to soybean ENOD2 cDNA was isolated on the basis of homology to ENOD2.] Nms-30 and A2ENOD2 must be regulated differently from nodulins such as leghemoglobin and similarly regulated nodulins described in Dunn et al. (1988), which are expressed in invaded nodules but not in empty nodules. Other nodulins that appear to be regulated in the same fashion as leghemoglobin include those corresponding to the nodule-specific translation spots seen in wild-type and invaded Fix ${ }^{-}$nodules for which we do not yet have corresponding cDNA clones (Fig. 1, panels $\mathrm{A}$ and $\mathrm{C}$ ).

The alfalfa ENOD2-like nodulin that we identified on the basis of its homology to a cloned soybean ENOD2 cDNA is highly homologous to soybean N-75, at both the nucleotide and deduced amino acid sequence level.
The ENOD2-gene product is a proline-rich protein that has been found to be expressed in all empty and invaded nodules for which its expression has been assayed (Govers et al. 1986; Moerman et al. 1987; this study). Because of its amino acid composition, it is likely that ENOD2 is involved in formation of the nodule structure as a cell-wall structural protein (Frannsen et al. 1987).

The role of Nms-30 in nodule development is less clear. Nms-30 is structurally related to $\mathrm{N}-40^{\prime}$ of pea (Govers et al. 1985, 1986) and Nvs-40 of Vicia sativa (Moerman et al. 1987); both Nms-30 and Nvs-40 can be immunoprecipitated by antiserum directed against $\mathrm{N}-40$ ' of pea (T. Bisseling, unpubl.). It is especially interesting to compare the synthesis of Nms-30 in empty alfalfa nodules to the synthesis of N-40' and Nvs-40 in pea and $V$. sativa nodules that were elicited by $A$. tumefa- 
ciens carrying the $R$. leguminosarum pSym. In pea, empty nodules are elicited by the $A$. tumefaciens strains; ENOD2, but not $\mathrm{N}-40^{\prime}$, is expressed in these nodules (Govers et al. 1986). In contrast, A. tumefaciens carrying the $R$. leguminosarum pSym elicits invaded nodules on $V$. sativa in which both ENOD2 and Nvs-40, but not leghemoglobin or other late nodulins, are expressed. Because $\mathrm{N}-40^{\prime}$ is not found in the empty pea nodules, the $\mathrm{N}-40^{\prime}$-gene product land by extension the Nvs-40- and Nms-30-gene products in V. sativa and alfalfa, respectively) cannot play an essential structural role in nodule development. $\mathrm{Nms}-30$ is equivalent to n-38 (J. Hanks Norris, pers. comm.), the only nodulin detected in empty alfalfa nodules elicited by the "haloless" $R$. meliloti exoH mutants (Leigh et al. 1987). exoH mutants fail to succinylate the Calcofluor-binding exopolysaccharide. The empty nodules obtained with exoH mutants have aborted infection threads (Leigh et al. 1987); in contrast, those elicited by exoB mutants do not (Finan et al. 1985).

We examined several $R$. meliloti exo mutants for their ability to synthesize the periplasmically localized cyclic $\beta(1 \rightarrow 2)$ glucan, the synthesis of which requires the $n d v$ loci. We found that $R$. meliloti exoA, exoB, and exo $F$ mutants synthesized the cyclic $\beta(1 \rightarrow 2)$ glucan but that an exoC mutant was defective in cyclic glucan synthesis. $A$. tumefaciens exoC mutants were also found to be pleiotropically defective in cyclic $\beta(1 \rightarrow 2)$ glucan production, as well as exopolysaccharide production /Cangelosi et al. 1987). Similarly, Thomashow et al. (1987) and Marks et al. (1987) isolated A. tumefaciens Virmutants (characteristic of $c h v$ mutants), which are Calcofluor dark (i.e., exo mutants) and are defective in a gene homologous to exoC.

The studies presented here demonstrate that empty alfalfa nodules elicited by $R$. meliloti exo and $n d v \mathrm{mu}-$ tants or by $A$. tumefaciens strains carrying the $R$. meliloti nod genes are not only cytologically similar to each other but are biochemically similar as well. All of these empty nodules are apparently blocked at a similar stage of nodule development. From this, we conclude that (1) the $R$. meliloti nod genes, when transferred to A. tumefaciens, are sufficient to induce a nodule structure and the expression of alfalfa A2ENOD2 and Nms-30, and (2) the exo and $n d v$ genes, their products, or the oligo- and polysaccharides themselves are involved in the production of a signal or structure that is necessary for the next stage of nodule development: invasion of the developing nodule. Moreover, it is likely that a $R$. meliloti mutant that synthesized neither the $n d v$ - nor exo-gene product would also elicit an empty nodule. Although a double exo-ndv R. meliloti mutant has not been constructed, $R$. meliloti exoC mutants fail to synthesize either the excreted acidic polysaccharide or the cyclic $\beta(1 \rightarrow 2)$ glucan but, nevertheless, elicit empty nodules that synthesize both Nms-30 and the ENOD2-like nodulin.

It is important to point out that wild-type $A$. tumefaciens strains carrying the $R$. meliloti nod genes are not capable of eliciting invaded nodules, despite the fact that wild-type $A$. tumefaciens produces both an exopolysac- charide and a cyclic $\beta(1 \rightarrow 2)$ glucan, which are similar to those produced by $R$. meliloti (Dell et al. 1983; Sutherland 1985; Cangelosi et al. 1987). Because $R$. meliloti exo and $n d v$ mutants fail to elicit invaded nodules, the simplest conclusion is that the exo- and ndv-gene products are necessary but not sufficient for nodule invasion and that additional $R$. meliloti 'invasiveness' genes remain to be discovered. On the other hand, it is possible that the $A$. tumefaciens exopolysaccharide and/ or cyclic glucan differ sufficiently from those of $R$. meliloti to be ineffective in nodule invasion. Another possibility is that $A$. tumefaciens elicits a defense response from the plant, which blocks further nodule development.

The presence of the Ti plasmid in $A$. tumefaciens carrying the $R$. meliloti nod genes had no apparent effect on the phenotype of the elicited nodules, and $A$. tumefaciens not carrying the nod genes failed to elicit either nodules or nodule-specific products. These results suggest that the synthesis of Nms-30 and the A2ENOD2like nodulin are nodulin-specific events and do not reflect a response to the presence of a potential pathogenic bacterium. The presence of a $\operatorname{chv} B$ mutation in an $A$. tumefaciens strain carrying the nod genes also had no effect on the elicitation of empty nodules. This latter result was predicted because $R$. meliloti ndv $B$ mutants elicit empty nodules. On the other hand, a different result was obtained in the Rhizobium phaseolus-bean symbiosis in which $A$. tumefaciens $c h v B$ mutants carrying $R$. phaseolus nod genes were deficient in eliciting any nodule structure (van Veen et al. 1987). The reason for this difference between the alfalfa and bean systems is not clear. The studies in the bean system were done with $A$. tumefaciens transconjugants containing the entire $R$. phaseoli pSym, whereas those in alfalfa utilized A. tumefaciens transconjugants carrying only the $R$. meliloti nod region. Perhaps other functions on the pSym prevent nodule structure development in an $A$. tumefaciens $c h v B$ background.

There are several possibilities for the roles of exopolysaccharides and cyclic $\beta(1 \rightarrow 2)$ glucans in nodule development. One is that the exopolysaccharide and cyclic glucan mediate recognition and attachment of rhizobia to the susceptible root hairs on the plant. $A$. tumefaciens $\operatorname{chv} A$ and $c h v B$ mutants that are defective in cyclic glucan are defective in cell attachment. Another possibility is that the cyclic glucan and exopolysaccharide might provide a milieu for rhizobial degradative enzymes that digest cell walls of the plant, initiating invasion. Alternatively, the rhizobial exopolysaccharide or cyclic glucan could be substrates for plant degradative enzymes, which could provide sugar building blocks for the synthesis of the infection thread, or the exopolysaccharide and glucan are substrates for enzymatic activities that produce oligosaccharin signal molecules, which might trigger invasion and infection thread formation. Another possibility is that the exopolysaccharide and cyclic glucan are involved in disarming a plant host defense response.

Finally, this study has emphasized the similarity of 
the plant response, cytologically and biochemically, to $A$. tumefaciens strains carrying the $R$. meliloti nod genes and $R$. meliloti exo and $n d v$ mutants. However, the $A$. tumefaciens-elicited empty nodules were fewer in number and larger than the exo and $n d v R$. meliloti-elicited empty nodules. We are trying to find biochemical markers that are a hallmark of this difference.

\section{Materials and methods}

\section{Bacterial strains and culture conditions}

The bacterial strains used in this study are listed in Table 2. Strains were grown on TY media (Miller) in the following concentrations of antibiotics, when appropriate: $20 \mu \mathrm{g} / \mathrm{ml}$ neomycin and $2.5 \mu \mathrm{g} / \mathrm{ml}$ tetracycline.

\section{Root nodules}

Alfalfa seeds (Iroquois) were surface sterilized for $10 \mathrm{~min}$ in concentrated sulfuric acid, rinsed copiously with sterile water, and imbibed for 3-4 hr in several changes of sterile water, which was agitated continuously. Seeds were germinated and grown on Nod media (Meade et al. 1982) containing $1.2 \%$ agar in $5.5 \times 4$-inch polycarbonate Nalgene jars that had holes drilled in the covers and were outfitted with foam bungs to maintain sterility. About 30-50 plants were grown per jar. For germination, the jars were incubated upside down; the next day, the seedlings were laid flat on the media and were grown overnight with the polycarbonate jar at a slant. The third day, the plants were inoculated with $1 \times 10^{9}$ bacteria per jar, placed in the greenhouse or growth chamber at a slant, and grown at $20-24^{\circ} \mathrm{C}$ on a $16-\mathrm{hr}$ light, 8 -hr dark cycle. Nodules were picked with tweezers $\sim 3-4$ weeks postinoculation and immediately frozen in liquid nitrogen. In the case of empty nodules, nodulated root segments were harvested because nodules were too small for clean dissection. As controls, 5-day-old uninoculated roots, 10-day-old uninoculated etiolated seedlings, and 4-weekold roots grown in the presence of $A$. tumefaciens were frozen in liquid nitrogen. All tissue was stored at $-70^{\circ} \mathrm{C}$ prior to use.

\section{Microscopy}

Alfalfa nodules were fixed and prepared for light microscopy, as described in Hirsch et al. (1983).

\section{RNA preparation}

RNA was prepared as described previously (Dunn et al. 1988). The polyadenylated fraction was isolated using an oligo(dT)cellulose column as described.

\section{In vitro translation and gel electrophoresis}

This procedure was done as described previously using $\left[{ }^{35} \mathrm{~S}\right] \mathrm{me}$ thionine and rabbit reticulocyte lysate (Dunn et al. 1988). The ${ }^{14} \mathrm{C}$ molecular-weight standards (New England Nuclear) used were phosphorylase B $(97.4 \mathrm{kD})$, bovine serum albumin 169.0 $\mathrm{kD})$, ovalbumin $(46.0 \mathrm{kD})$, carbonic anhydrase $(30.0 \mathrm{kD})$, lactoglobulin A (18.4 kD), and cytochrome C (12.3 kD).

\section{Northern blots}

Total RNA $(1 \mu \mathrm{g})$ or $\operatorname{poly}(\mathrm{A})^{+}(10 \mathrm{ng})$ was run on $1 \%$ agarose gels containing formaldehyde and blotted to GeneScreen (DuPont), as described (Maniatis et al. 1982).

\section{Leghemoglobin cDNA}

Leghemoglobin cDNAs were isolated from a $\lambda$ gt 11 library, constructed by A. Dow (pers. comm.), on the basis of hybridization to a previously isolated leghemoglobin cDNA clone (Dunn et al. 1988). The cDNAs were subcloned in the plasmid Bluescribe- (Stratagene, Inc.), using the EcoRI site. A clone designated pBl-17 that had a $0.55-\mathrm{kb}$ insert was chosen.

\section{Alfalfa ENOD2 cDNA probe}

A fourfold degenerate probe of sequence TGGTGGC(C/T)TTTCTCATGAGGA/A/T)TGG was synthesized in our department by J. Smith and L. Kizilay. This corresponds to a repeated sequence of a soybean nodulin gene that codes for N-75 (also called ENOD2), a nodulin that is synthesized early during soybean nodule development (Frannsen et al. 1987). The oligonu-

Table 2. Bacterial strains and plasmids

\begin{tabular}{lll}
\hline Strains & Relevant markers & Source or reference \\
\hline R. meliloti & & Meade et al. (1982) \\
Rm1021 & str-r derivative of SU47 & Leigh et al. (1985) \\
Rm7023 & Rm1021 (exoA :: Tn5) & Leigh et al. (1985) \\
Rm7094 & Rm1021 (exoB :: Tn5) & Leigh et al. (1985) \\
Rm7020 & Rm1021 (exoC:: Tn5) & Leigh et al. (1985) \\
Rm7027 & Rm1021 (exoC:: Tn5) & Leigh et al. (1985) \\
Rm7055 & Rm1021 (exoF :: Tn5) & Ditta et al. (1980) \\
Rm102F34 & nal-r wild-type strain & Dylan et al. (1986) \\
Rm ndvA-LI & Rm102F34 (ndvA :: Tn5) & Dylan et al. (1986) \\
Rm ndvB-TY7 & Rm102F34 (ndvB:: Tn5) & Dylan et al. (1986) \\
Rm ndvB-TY9 & Rm102F34 (ndvB:: Tn5) & Garfinkel et al. (1981) \\
A. tumefaciens & & Watson et al. (1975) \\
At136 & Ti plasmid cured & Douglas et al. (1985) \\
At348 & wild type & \\
At1038 & At348 (chvB :: Tn5) & M. Honma (unpubl.) \\
Plasmid & & R. meliloti nodD1, nodABC, nodEFGH, nodD3 \\
pMH36 & &
\end{tabular}


cleotide was end labeled with ${ }^{32} \mathrm{P}$, using $\mathrm{T} 4$ polynucleotide kinase (Maniatis et al. 1982) and used to probe the $\lambda$ gtll alfalfa nodule cDNA library according to a method devised by R. Cate (pers. comm.). Five hybridizing plaques were detected among $\sim 5 \times 10^{4}$ plaques screened. A $0.3-\mathrm{kb}$ insert in one of these five clones was subcloned in Bluescribe- at the EcoRI site, creating $\mathrm{pBl}-\mathrm{A} 2 \mathrm{ENOD} 2$. The $0.3-\mathrm{kb}$ insert in pBl-A2ENOD2 was sequenced by the dideoxy method using double-stranded plasmid template DNA, as described by Chen and Seeburg (1985). The nucleotide sequence is shown in Figure 2A. It shows $81 \%$ homology with the soybean N-75 sequence. The translated peptide, shown in Figure 2B, shows $70 \%$ homology with a peptide fragment of soybean N-75.

\section{Alfalfa ribosomal probe}

A $\lambda$ gtll plaque was isolated from the alfalfa nodule library described above that hybridized to a soybean ribosomal clone, pRKDR2 (Eckenrode et al. 1985; J. Key and R. Nagao, pers. comm.). A $0.5-\mathrm{kb}$ EcoRI fragment from this clone was subcloned into Bluescribe-, resulting in pBl-18r. pBl-18r corresponds to the large rRNA subunit.

\section{Calcofluor flourescence tests}

R. meliloti strains were grown on LB plates (Miller 1972) containing $200 \mu \mathrm{g} / \mathrm{ml}$ Calcofluor (Sigma) and checked for fluorescence as described in Leigh et al. (1985).

\section{Cyclic glucan analysis}

The procedure of Miller et al. (1986) was followed for cyclic glucan analysis. $R$. meliloti or $A$. tumefaciens strains were grown in YM media, supplemented with antibiotics where appropriate. $R$. meliloti exoC strains 7020 and 7027 did not grow in YM; these strains were supplemented with $0.1 \mathrm{M} \mathrm{NaCl}$ for growth. Cells were harvested in log phase by centrifugation and extracted with TCA, neutralized, and lyophilized (Miller et al. 1986). The extracts were applied to a $1.6 \times 100-\mathrm{cm}$ Sephadex G-50 column and eluted with 7\% 1-propanol and $50 \mathrm{mM}$ ammonium acetate. Fractions $(1.8 \mathrm{ml})$ were collected and assayed for total carbohydrate by the phenol-sulfuric acid method (Hanson and Phillips 1981).

\section{Linkage analysis}

All samples were methylated according to the procedures described by Ciucanu and Kerek (1984). The permethylated alditol acetates were analyzed by GLC on a 30-m, fused silica, capillary column coated with DB-1701 (J \& W Scientific, Rancho Cardova, California), and GLC-MS with a FinniganMAT 312 (San Jose, California) double-focusing instrument fitted with a combined electron- and chemical-ionization source. The reagent gas used while in the chemical ionization mode was ammonia with an ion-source temperature of $125^{\circ} \mathrm{C}$. Electron-ionization voltage was $70 \mathrm{eV}$ and the ion-source temperature was $200^{\circ} \mathrm{C}$. Additional information on methods of complex carbohydrate structural analysis can be found in Reinhold (1986).

\section{Molecular weight analysis}

The cyclic glucans were analyzed by DCI, following sample permethylation on a VG ZAB-SE high-resolution double-focusing instrument (VG Analytical Ltd., Manchester, United Kingdom), which was operated at $8 \mathrm{kV}$ accelerating voltage. Ap- proximately $3-10 \mu \mathrm{g}$ of derivatized sample was placed on the DCI probe and desorbed with a programmed heating current.

\section{Acknowledgments}

We thank Ms. Chan for technical assistance with permethylation analysis of the carbohydrate samples, A. Dow for the alfalfa nodule cDNA library, R. Saganich for microscopy, P. Guevara and $K$. Miller for help with and advice on the carbohydrate assays, respectively, $M$. Thomashow and $R$. Cate for unpublished manuscripts, and J. Key and R. Nagao for pRKDR2. This work was supported by a grant from Hoechst AG to Massachusetts General Hospital and by the National Science Foundation and the National Institutes of Health for instrumentation support to V.N.R.

\section{References}

Cangelosi, G.A., L. Hung, V. Puvanesarajah, G. Stacey, D.A. Ozga, J.A. Leigh, and E.W. Nester. 1987. Common loci for Agrobacterium tumefaciens and Rhizobium meliloti exopolysaccharide synthesis and their roles in plant interactions. I. Bacteriol. 169: 2086-2091.

Chen, E.Y. and P.H. Seeburg. 1985. Supercoil sequencing: A fast and simple method for sequencing plasmid DNA. DNA 4: $165-170$.

Ciucanu, I. and F. Kerek. 1984. A simple and rapid method for the permethylation of carbohydrates. Carbohydr. Res. 131: 209-217.

Dell, A., W.S. York, M. McNeil, A.G. Darvill, and P. Albersheim. 1983. The cyclic structure of $\beta$-D- $(1 \rightarrow 2)$-linked D glucans secreted by Rhizobia and Agrobacteria. Carbohydr. Res. 117: 185-200.

Ditta, G., S. Stanfield, D. Corbin, and D.R. Helinski. 1980. Broad host range DNA cloning system for Gram-negative bacteria: Construction of a gene bank of Rhizobium meliloti. Proc. Natl. Acad. Sci. 77: 7347-7351.

Douglas, C.J., W. Halperin, and E.W. Nester. 1982. Agrobacterium tumefaciens mutants affected in attachment to plant cells. J. Bacteriol. 152: 1265-1275.

Douglas, C.J., R.J. Staneloni, R.A. Rubin, and E.W. Nester. 1985. Identification and genetic analysis of an Agrobacterium tumefaciens chromosomal virulence region. $J$. Bacteriol. 161: 850-860.

Dunn, K., R. Dickstein, R. Feinbaum, B. Burnett, T.K. Peterman, G. Thoidis, H.M. Goodman, and F.M. Ausubel. 1988. Developmental regulation of nodule-specific genes in alfalfa root nodules. Mol. Plant-Microbe Interactions 1: $66-74$.

Dylan, T., L. Ielpi, S. Stanfield, L. Kashyap, C. Douglas, M. Yanofsky, E. Nester, D.R. Helinski, and G. Ditta. 1986. Rhizobium meliloti genes required for nodule development are related to chromosomal virulence genes in Agrobacterium tumefaciens. Proc. Natl. Acad. Sci. 83: 4403-4407.

Eckenrode, V.K., J. Arnold, and R.B. Meagher. 1985. Comparison of the nucleotide sequence of soybean 18S rRNA with the sequences of other small subunit rRNAs. J. Mol. Evol. 21: $259-269$.

Finan, T.M., A.M. Hirsch, J.A. Leigh, E. Johansen, G.A. Kuldau, S. Deegan, G.C. Walker, and E. Signer. 1985. Symbiotic mutants of Rhizobium meliloti that uncouple plant from bacterial differentiation. Cell 40: 869-877.

Franssen, H.J., J.-P. Nap, T. Gloudemans, W. Stiekema, H. van Dam, F. Govers, J. Louwerse, A. van Kammen, and T. Bisseling. 1987. Characterization of cDNA for nodulin-75 of 
soybean: A gene product involved in early stages of root nodule development. Proc. Natl. Acad. Sci. 84: 4495-4499.

Friedman, A.M., S.R. Long, S.E. Brown, W.J. Buikema, and F.M. Ausubel. 1982. Construction of a broad host range cosmid cloning vector and its use in the genetic analysis of Rhizobium mutants. Gene 18: 289-296.

Garfinkel, D., R. Simpson, L. Ream, F. White, M. Gordon, and E. Nester. 1981. Genetic analysis of crown gall: Fine structure mapping of the T-DNA by site-directed mutagenesis. Cell 27: 143-153.

Geremia, R.A., S. Cavaignac, A. Zorreguieta, N. Toro, J. Olivares, and R.A. Ugalde. 1987. A Rhizobium meliloti mutant that forms ineffective pseudonodules in alfalfa produces exopolysaccharide but fails to form $\beta-(1 \rightarrow 2)$ glucan. $J$. Bacteriol. 169: 880-884.

Govers, F., T. Goudemans, M. Moerman, A. van Kammen, and T. Bisseling. 1985. Expression of plant genes during the development of pea root nodules. EMBO /. 4: 861-867.

Govers, F., M. Moerman, J.A. Downie, P. Hooykaas, H.J. Franssen, J. Louwerse, A. van Kammen, and T. Bisseling. 1986. Rhizobium nod genes are involved in the induction of an early nodulin gene. Nature 323: 564-566.

Halverson, L.J. and G. Stacy. 1986. Signal exchange in plantmicrobe interactions. Microbiol. Rev. 50: 193-225.

Hanson, R.S. and J.A. Phillips. 1981. Chemical composition. In Manual of methods for general bacteriology led. P. Gerhardt, R.G.E. Murray, R.N. Costilow, E.W. Nester, W.A. Wood, N.R. Kreig, and G.B. Phillips), pp. 328-364. American Society for Microbiology, Washington, D.C.

Hirsch, A.M., M. Bang, and F.M. Ausubel. 1983. Ultrastructural analysis of ineffective alfalfa nodules formed by nif :: Tn5 mutants of Rhizobium meliloti. J. Bacteriol. 155: 367-380.

Hirsch, A.M., K.J. Wilson, J.D.G. Jones, M. Bang, V.V. Walker, and F.M. Ausubel. 1984. Rhizobium meliloti nodulation genes allow Agrobacterium tumefaciens and Escherischia coli to form pseudonodules on alfalfa. I. Bacteriol. 158: 1133-1143.

Kondorosi, E. and A. Kondorosi. 1986. Nodule initiation on plant roots by Rhizobium. Trends Biochem. Sci. 11: 296299.

Lang-Unnasch N. and F.M. Ausubel. 1985. Nodule-specific polypeptides from alfalfa root nodules and from ineffective nodules lacking nitrogenase. Plant Physiol. 77: 833-839.

Lang-Unnasch, N., K. Dunn, and F.M. Ausubel. 1985. Symbiotic nitrogen fixation: Developmental genetics of nodule formation. Cold Spring Harbor Symp. Quant. Biol. 50: 555563.

Leigh, J.A., E.R. Signer, and G.C. Walker. 1985. Exopolysaccharide-deficient mutants of Rhizobium meliloti that form ineffective nodules. Proc. Natl. Acad. Sci. 82: 6231-6235.

Leigh, J.A., J.W. Reed, J.F. Hanks, A.M. Hirsch, and G.C. Walker. 1987. Rhizobium meliloti mutants that fail to succinylate their Calcofluor-binding exopolysaccharide are defective in nodule invasion. Cell 51: 579-587.

Maniatis, T., E.F. Fritsch, and J. Sambrook. 1982. Molecular cloning: A laboratory manual. Cold Spring Harbor Laboratory, Cold Spring Harbor, New York.

Marks, J.R., T.J. Lynch, J.E. Karlinsey, and M.F. Thomashow. 1987. Agrobacterium tumefaciens virulence locus $p s c A$ is related to the exoC locus of Rhizobium meliloti. I. Bacteriol. 169: 5835-5837.

Meade, H.M., S.R. Long, G.B. Ruvkun, S.E. Brown, and F.M. Ausubel. 1982. Physical and genetic characterization of symbiotic and auxotropic mutants of Rhizobium meliloti induced by transposon Tn5 mutagenesis. J. Bacteriol. 149: 114-122.
Miller, J.H. 1972. Experiments in molecular genetics. Cold Spring Harbor Laboratory, Cold Spring Harbor, New York.

Miller, K.J., E.P. Kennedy, and V.N. Reinhold. 1986. Osmotic adaptation by Gram-negative bacteria: Possible role for periplasmic oligosaccharides. Science 231: 48-51.

Moerman, M., J.-P. Nap, F. Govers, R. Schilperoort, A. van Kammen, and T. Bisseling. 1987. Rhizobium nod genes are involved in the induction of two early nodulin genes in Vicia sativa root nodules. Plant Mol. Biol. 9: 171-179.

Peters, N.K., J.W. Frost, and S.R. Long. 1986. A plant flavone, luteolin, induces expression of Rhizobium meliloti nodulation genes. Science 233: 977-980.

Puvanesarajah, V., F. Schell, G. Stacey, C.J. Douglas, and E.W. Nester. 1985. A role for $\beta$-2-glucan in the virulence of Agrobacterium tumefaciens. J. Bacteriol. 164: 102-106.

Redmond, J.W., M. Batley, M.A. Djordjevic, R.W. Innes, E.L. Kuempel, and B.G. Rolfe. 1986. Flavones induce expression of nodulation genes in Rhizobium. Nature 323: 632-635.

Reinhold, V.N. 1986. Structural elucidation of complex carbohydrates. In Mass spectroscopy in biomedical research led. S.S. Gaskell), pp. 181-213. John Wiley and Sons, New York.

Sutherland, I.W. 1985. Biosynthesis and composition of gramnegative bacterial extracellular and wall polysaccharides. Annu. Rev. Microbiol. 39: 243-270.

Thomashow, M.F., J.E. Karlinsey, J.R. Marks, and R.E. Hurlbert. 1987. Identification of a new virulence locus in Agrobacterium tumefaciens that affects polysaccharide composition and plant cell attachment. J. Bacteriol. 169: 3209-3216.

Truchet, G., F. DeBelle, J. Vasse, B. Terzaghi, A.-M. Garnerone, C. Rosenberg, J. Batut, F. Maillet, and J. Denarie. 1985. Identification of a Rhizobium meliloti pSym2011 region controlling the host specificity of root hair curling and nodulation. I. Bacteriol. 164: 1200-1210.

van Veen, R.J.M., H. den Dulk-Ras, R.A. Schilperoort, and P.J.J. Hooykaas. 1987. Chromosomal nodulation genes: Sym plasmid containing Agrobacterium strains need chromosomal virulance genes $(\operatorname{chv} A$ and $\operatorname{chv} B)$ for nodulation. Plant Mol. Biol. 8: 105-108.

Verma, D.P.S. and S.R. Long. 1983. Molecular biology of the Rhizobium legume symbiosis In Intracellular symbioses (ed. K. Jeon), pp. 211-245. Academic Press, New York.

Watson, B., T.C. Currier, M.P. Gordon, M.-D. Chilton, and E.W. Nester. 1975. Plasmid required for virulence of Agrobacterium tumefaciens. J. Bacteriol. 123: 255-264. 


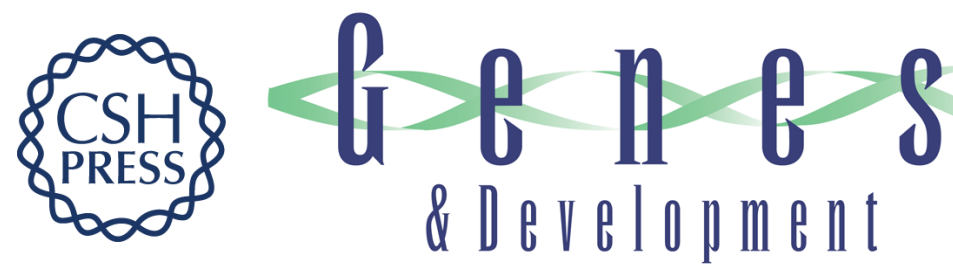

\section{Expression of nodule-specific genes in alfalfa root nodules blocked at an early stage of development.}

R Dickstein, T Bisseling, V N Reinhold, et al.

Genes Dev. 1988, 2:

Access the most recent version at doi:10.1101/gad.2.6.677

References This article cites 37 articles, 19 of which can be accessed free at:

http://genesdev.cshlp.org/content/2/6/677.full.html\#ref-list-1

License

Email Alerting

Service

Receive free email alerts when new articles cite this article - sign up in the box at the top right corner of the article or click here.

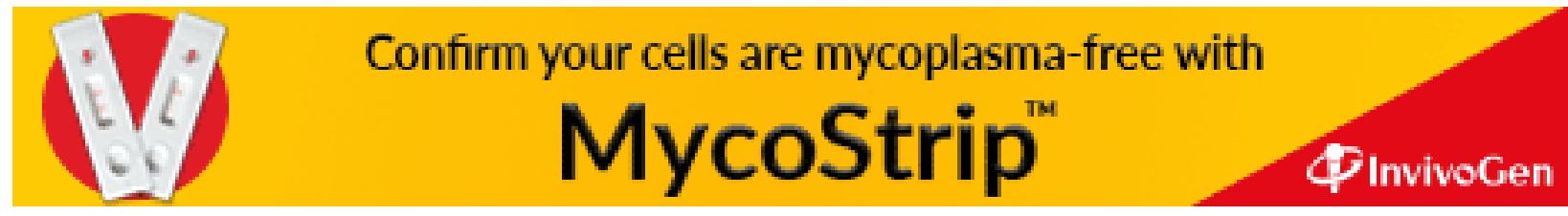

